\title{
Microhardness studies on nonlinear optical $L$-alanine single crystals
}

\author{
R HANUMANTHARAO ${ }^{\dagger}$ and S KALAINATHAN ${ }^{\ddagger * *}$ \\ $\dagger$ Vignan's Institute of Information Technology, Physics Division, Visakhapatnam 530 049, India \\ ¥Crystal Research Centre, VIT University, Vellore 632 014, India
}

MS received 22 November 2011; revised 17 September 2012

\begin{abstract}
Vickers and Knoop microhardness tests were carried out on grown $L$-alanine single crystals by slow evaporation technique over a load range of 10-50 g on selected broad (2 03$)$ plane. Vickers $\left(H_{\mathrm{v}}\right)$ and $\mathrm{Knoop}\left(H_{\mathrm{k}}\right)$ microhardness for the above loads were found to be in the range of $60-71 \mathrm{~kg} / \mathrm{mm}^{2}$ and $35-47 \mathrm{~kg} / \mathrm{mm}^{2}$, respectively. Vickers microhardness number $\left(H_{v}\right)$ and Knoop microhardness number $\left(H_{k}\right)$ were found to increase with increasing load. Meyer's index number $(n)$ calculated from $H_{\mathrm{v}}$ shows that the material belongs to the soft material category. Using Wooster's empirical relation, the elastic stiffness constant $\left(c_{11}\right)$ was calculated from Vickers hardness values. Young's modulus was calculated using Knoop hardness values. Hardness anisotropy has been observed in accordance with the orientation of the crystal.
\end{abstract}

Keywords. Organic compounds; mechanical properties; hardness; anisotropy.

\section{Introduction}

Nonlinear optical applications find a variety of applications such as frequency conversion, light modulation, optical switching, optical memory storage and optical second harmonic generation (SHG) (Wang et al 1999; Chenthamarai et al 2000). The nonlinear optical crystal of $L$-alanine is the simplest naturally occurring chiral amino acid with a non-reactive hydrophobic methyl group $\left(-\mathrm{CH}_{3}\right)$ as a side chain. $L$-alanine has the zwitterionic form $\left(+\mathrm{NH}_{3}-\mathrm{C}_{2} \mathrm{H}_{4}-\right.$ $\mathrm{COO}^{-}$), which is the simplest acentric member of the amino acid family crystallized in orthorhombic crystal system with space group $P 22_{1} 2_{1} 2_{1}$ and cell parameters $a=6.032 \AA$, $b=12.343 \AA, c=5.784 \AA ; \alpha=\beta=\gamma=90^{\circ}$. From thermal analysis, melting point of $L$-alanine compound was reported as $297^{\circ} \mathrm{C}$ and by optical transmittance spectrum, the lower cut-off wavelength was reported as $245 \mathrm{~nm}$ (Lydia et al 2009). SHG of $L$-alanine compound is found to be 0.20 times higher than standard potassium dihydrogen phosphate (KDP) crystal (Jaikumar et al 2009). However, there is no discussion reported on the microhardness studies for this crystal to the best of our knowledge. The importance of hardness for crystals has been discussed by various researchers (Nimisha et al 1997; Pandya et al 1999; Subhadra et al 2000; Rao et al 2002; Sangita et al 2005) for various applications, since mechanical strength is one of the important properties of any device materials represented by its hardness. As crystal $L$-alanine is available as a small-sized sample, it is convenient to take measurements at low loads. This low load hardness is called microhardness. Measurement of hardness provides useful information about the mechanical properties such as elastic constants (Wooster

\footnotetext{
*Author for correspondence (kalainathan@yahoo.com)
}

1953) and yield strength (Westbrook 1958), etc. The hardness is estimated from the ratio of the load applied on indenter to the area of the impression left on the specimen. Both Vickers and Knoop hardness tests were carried out on the cleavage face (2 03 3) of the grown crystal. Meyer's index $(n)$ was found to be $>1.6$ showing soft material characteristics. Using Wooster's empirical relation, the elastic stiffness constant $\left(c_{11}\right)$ was calculated from Vickers hardness values. For calculating Young's modulus, Knoop indentations were made on similar (2 03 ) face by Knoop's diamond pyramidal indenter. There is a systematic approach followed to extract the accurate hardness data for $L$-alanine single crystals.

\section{Experimental}

\subsection{Crystal growth}

High purity $L$-alanine $(99.9 \%$ purity) salt purchased from Sigma Aldrich was used for the crystal growth process. Initially, the salt of $L$-alanine was dissolved in excess triple-distilled water. The solution was filtered twice using Whatman filter paper to remove the impurities collected in the solution. The process of recrystallization takes place thrice and saturated solution of $L$-alanine was prepared from the recrystallized salt, then mixed in aqueous solution according to the solubility data (Lydia et al 2009). The saturated solution was taken in a beaker with perforated cover making few small holes to facilitate slow evaporation and placed in a constant temperature bath controlled to an accuracy of $\pm 0.01{ }^{\circ} \mathrm{C}$. Good quality single crystals with well defined morphology were extracted after a growth period of 16 days. The extracted single crystals of $L$-alanine are 
presented in figure 1. Morphological studies of $L$-alanine single crystal have already been reported by Lydia et al (2009). Good quality crystals were selected for static indentation tests.

\subsection{Microhardness}

Mechanical characterization of $L$-alanine crystals was done by Vickers and Knoop microhardness studies at room temperature. Crystal with flat and smooth (2 03 3) plane chosen for static indentation tests was mounted on the clamping devices to the base of the microscope controlled by $\mathrm{XY}$ travel stage of dimensions $50 \times 50 \mathrm{~mm}\left(2^{\prime} \times 2^{\prime}\right)$. Now, the selected face was indented gently by loads varying from 10 to $50 \mathrm{~g}$ for a dwell period of $10 \mathrm{~s}$ using both Vickers diamond pyramid indenter and Knoop indenter attached to an incident ray research microscope (Mututoyo MH 112, Japan). Vickers indented impressions were approximately square in shape. Length of the two diagonals was measured by a calibrated micrometer attached to the eyepiece of the microscope after unloading and the average was found out. For a particular load, at least five well defined indentations were considered and the average of all the diagonals $(d)$ was considered. $H_{\mathrm{v}}$ was calculated using the standard formula (Pal and Kar 2005):

$$
H_{\mathrm{v}}=1.8544 P / d^{2},
$$

where $P$ is the applied load in $\mathrm{kg}, d$ is in $\mathrm{mm}$ and $H_{\mathrm{v}}$ is in $\mathrm{kg} \mathrm{mm}^{-2}$.

The Knoop indented impressions were approximately rhombohedral in shape. Average diagonal length $(d)$ was considered for the calculation of Knoop microhardness number $\left(H_{\mathrm{k}}\right)$ using the relation (Pal and Kar 2005):

$$
H_{\mathrm{k}}=14 \cdot 229 P / d^{2} \text {, }
$$

where $P$ is the applied load in $\mathrm{kg}, d$ is in $\mathrm{mm}$ and $H_{\mathrm{k}}$ is in $\mathrm{kg} \mathrm{mm}^{-2}$.

Crack initiation and fragmentation become significant beyond $50 \mathrm{~g}$ of applied load. So hardness test could not

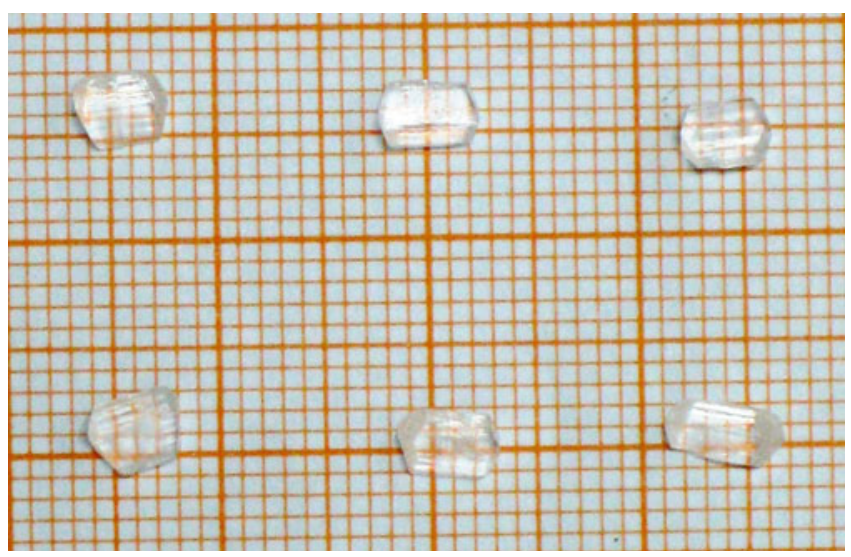

Figure 1. As grown good quality $L$-alanine single crystals. be carried out above this load. From Wooster's empirical relation (Wooster 1953),

$$
c_{11}=H_{\mathrm{v}}^{7 / 4} \text {. }
$$

\section{Results and discussion}

\subsection{Vickers microhardness}

Figure 2 shows variation of $H_{\mathrm{v}}$ as a function of applied load ranging from 10 to $50 \mathrm{~g}$ for $L$-alanine single crystals. It is very clear from the figure that $H_{\mathrm{v}}$ increases with increase in load. Meyer's index number was calculated from Meyer's law (as discussed by Jagannathan et al 2007), which relates the load and indentation diagonal length as

$$
\begin{aligned}
& P=k d^{n}, \\
& \log P=\log k+n \log d,
\end{aligned}
$$

where $k$ is the material constant and ' $n$ ' the Meyer's index.

The above relation (4) indicates that $H_{\mathrm{v}}$ should increase with $P$, if $n>2$ and decrease with $P$ when $n<2$. This is well satisfied as shown by figure 2 . In order to find the value of ' $n$ ', a graph is plotted for $\log P$ against $\log d$ (figure 3), which gives a straight line (after least square fitting). From the slope line, Meyer's index number ' $n$ ' was calculated and was found to be 2.14. According to Hanneman (1941), the values of $n$ were $1-1.6$ for hard materials and more than 1.6 for soft ones. Thus, $L$-alanine belongs to soft material category. The resistance pressure is defined as a minimum level of indentation load $(W)$ below which there is no plastic deformation (Gupta et al 2005). Hayes and Kendall (1973) proposed a relationship between indentation test load and indentation size to calculate $W$ using the equation

$$
W=k_{1} d^{n}-k_{2} d^{2},
$$

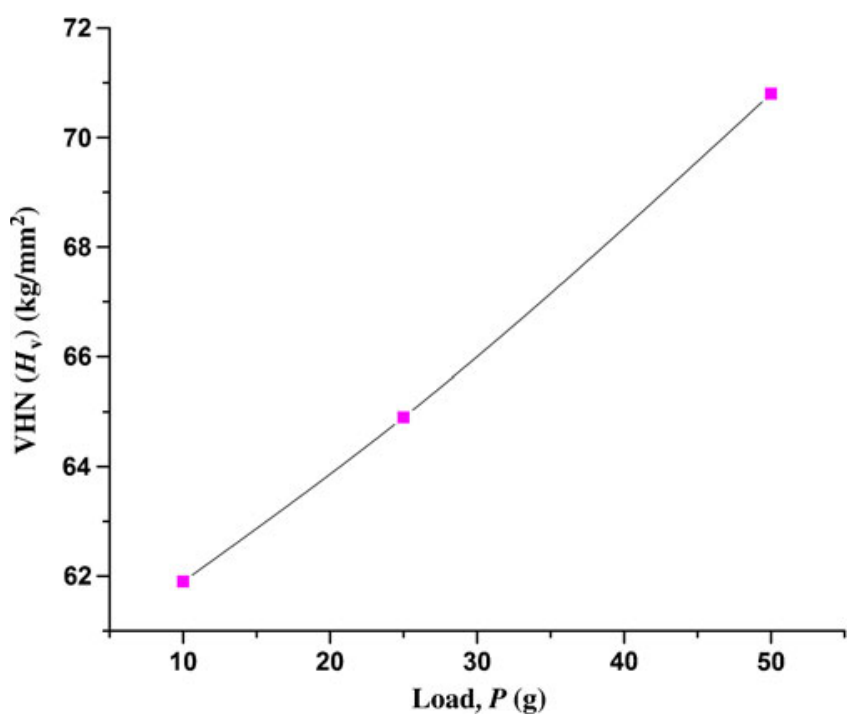

Figure 2. Variation of Vickers microhardness number $H_{\mathrm{v}}$ with load. 


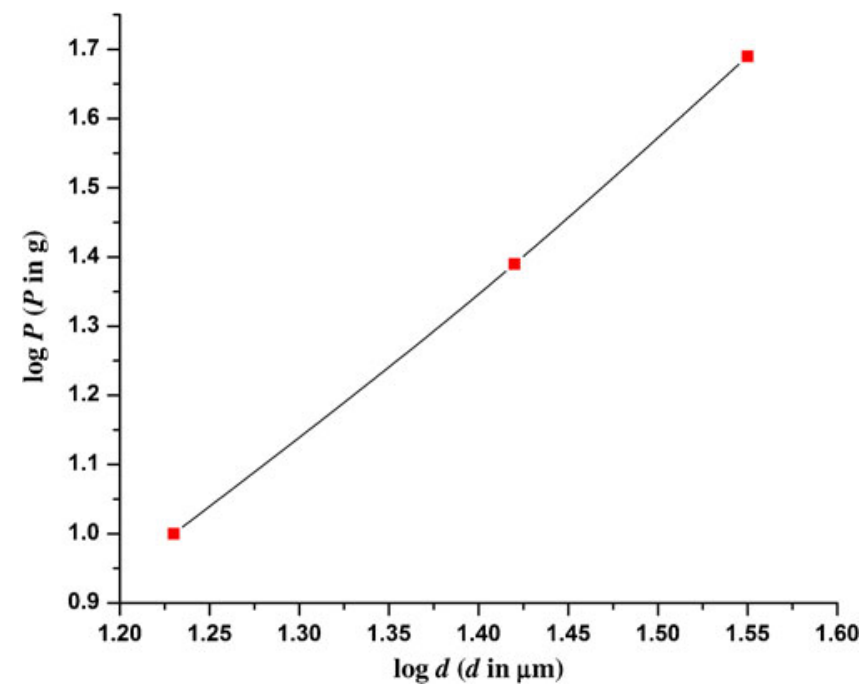

Figure 3. Graph between $\log P$ vs $\log d$.

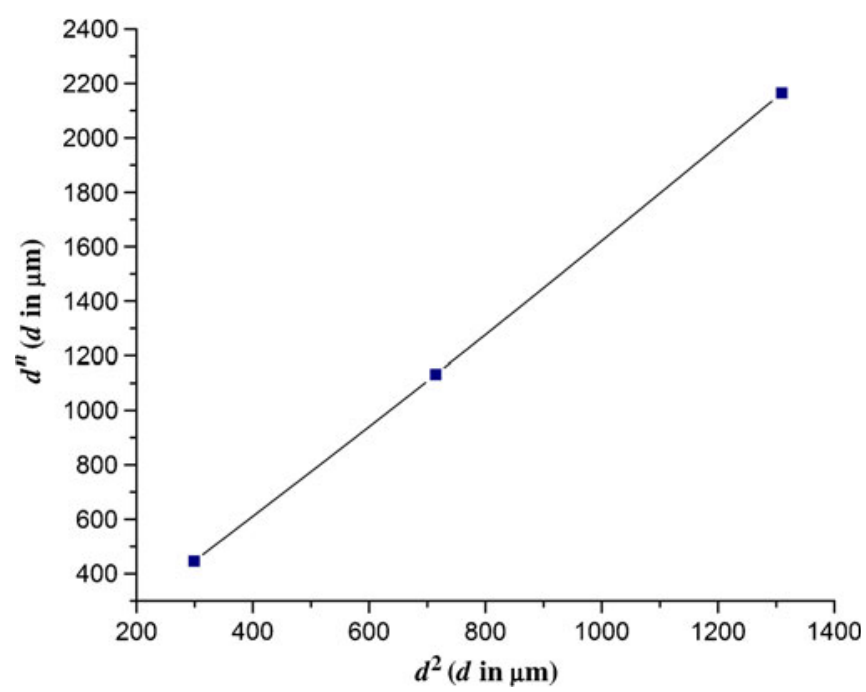

Figure 4. Plot between $d^{2}$ and $d^{n}$ of $L$-alanine crystal.

or

$$
d^{n}=\frac{W}{k_{1}}+\left(\frac{k_{2}}{k_{1}}\right) d^{2} .
$$

The plot of $d^{n}$ vs $d^{2}$ is a straight line (figure 4) having slope, $k_{2} / k_{1}$ and intercept, $W / k_{1}$. From these values, we have calculated the value of $W$ as $5.63 \mathrm{~g}$, where ' $W$ ' stands for small resistance pressure which is a function of the material under investigation, which represents the minimum load that causes indentation.

From figure 4 , using intercept $W / k_{1}$ and slope $k_{2} / k_{1}$, the value of $k_{1}$ and $k_{2}$ were calculated as $7.8 \times 10^{5} \mathrm{~kg} \mathrm{~m}^{-1}$ and $1.3 \times 10^{4} \mathrm{~kg} \mathrm{~m}^{-1}$, respectively.

Elastic stiffness constant $\left(c_{11}\right)$ was calculated by Wooster's (1953) empirical relation. Stiffness constant for different loads calculated from Vickers hardness values are shown in table 1.
Table 1. Variation of elastic stiffness constant $\left(c_{11}\right)$ and Young's modulus $(E)$ with load.

\begin{tabular}{lccc}
\hline $\begin{array}{l}\text { S1. } \\
\text { no. }\end{array}$ & $\begin{array}{c}\text { Load } \\
(g)\end{array}$ & $\begin{array}{c}c_{11} \\
\left(\times 10^{14} \mathrm{pa}\right)\end{array}$ & $\begin{array}{c}\text { Young's modulus, } \\
E(\mathrm{Gpa})\end{array}$ \\
\hline 1 & 10 & $4 \cdot 14$ & 3.51 \\
2 & 25 & $7 \cdot 00$ & 4.49 \\
3 & 50 & $12 \cdot 5$ & 9.50 \\
\hline
\end{tabular}

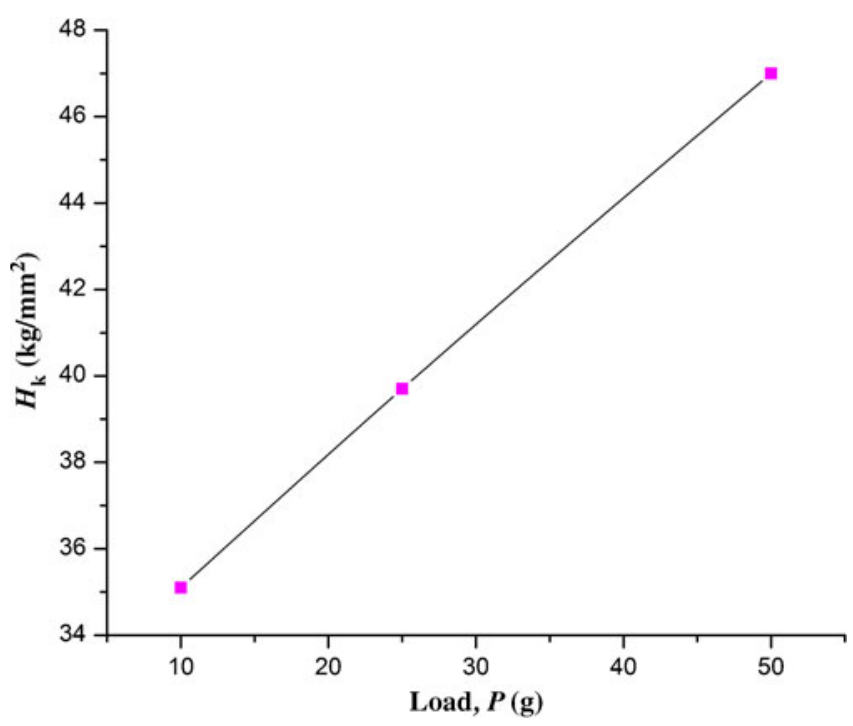

Figure 5. Variation of Knoops microhardness number $H_{\mathrm{k}}$ with load.

\subsection{Knoop microhardness}

A graph was plotted for Knoop hardness $\left(H_{\mathrm{k}}\right)$ against load $(P)$. The plot is shown in figure 5. From this measurement, it was found that as the load increases, the Knoop microhardness number also increases, which is due to the reverse indentation size effect (Sangwal 2009).

From Knoop microhardness measurements, Young's modulus $(E)$ of the crystal was calculated using the relation (Pal and Kar 2005),

$$
E=0.45 H_{\mathrm{k}} /\left(0.1406-\frac{b}{a}\right),
$$

where $H_{\mathrm{k}}$ is Knoop microhardness value at a particular load, and $b$ and $a$ are the shorter and longer Knoop indentation diagonals, respectively. The calculated Young's modulus for various loads is shown in table 1.

For studying crystal anisotropy, microhardness was measured by varying crystal orientations over a range of $0-360^{\circ}$ in steps of $30^{\circ}$. From figure 6 , it is very clear that variation was periodic. Variation in hardness number indicates the anisotropic nature of $L$-alanine crystal. Crystal structure and slip system play an important role in the observed variation of hardness with crystal orientation. Directional variation in hardness might be due to the change in orientation of 


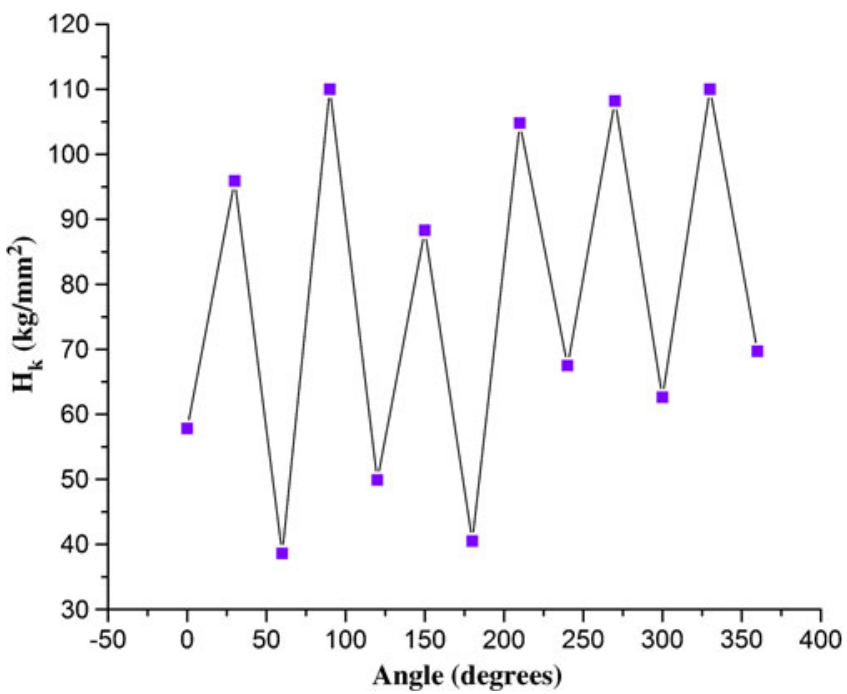

Figure 6. Anisotropy nature of $L$-alanine single crystal.

the slip system of the crystal with respect to the indenter (as discussed by Jagannathan et al 2007).

\section{Conclusions}

Vickers and Knoops microhardness for $L$-alanine crystal was calculated by the application of load in the range 10-50 g. The value of Meyer's index was calculated as $2 \cdot 14$, which suggests that $L$-alanine belongs to soft material category. The value of $c_{11}$ gives the idea of toughness of bonding between neighbouring atoms. Here, the small value of $c_{11}$ indicates that the binding forces between the ions are not quite strong. The periodic variation in hardness for the $\left(\begin{array}{lll}2 & 0 & 3\end{array}\right)$ face of $L$-alanine crystal exhibits anisotropic property.

\section{Acknowledgements}

The author acknowledges SAIF, IIT Madras, for providing morphological studies. The author also thanks VIT University for providing excellent research facilities.

\section{References}

Chenthamarai S, Jayaraman D, Ushasree $\mathrm{P}$ M, Meera K, Subramanian C and Ramasamy P 2000 Mater. Chem. Phys. 64 179

Gupta V, Bamzai K K, Kotru P N and Wanklyn B M 2005 Mater. Chem. Phys. 8964

Hayes C and Kendall E G 1973 Metallography 6275

Hanneman M 1941 Metall. Manchu 23135

Jagannathan K, Kalainathan S and Gnanasekaran T 2007 Mater. Lett. 614485

Jaikumar D, Kalainathan S and Bhagavan Narayana G $2009 \mathrm{~J}$. Cryst. Growth $\mathbf{3 1 2} 120$

Lydia C M, Sankar R, Indirani R M and Vasudevan S 2009 Mater. Chem. Phys. 114490

Nimisha V, Joshi M J, Shah B S and Joshi D R 1997 Bull. Mater. Sci. 20333

Pal T and Kar T 2005 Mater. Lett. 591400

Pandya G R, Bhavsar S R and Soni P H 1999 Bull. Mater. Sci. 2215

Rao K K, Surrender V and Saritha Rani B 2002 Bull. Mater. Sci. 25 641

Sangita R, Bajpai R and Bajpai A K 2005 Bull. Mater. Sci. 28529

Sangwal K 2009 Cryst. Res. Technol. 441019

Subhadra K G, Kishan Rao K and Sirdeshmukh D B 2000 Bull. Mater. Sci. 23147

Wang W S, Aggarwal M D, Choi J, Gebre T, Shields A D, Penn B G and Frazier D O 1999 J. Cryst. Growth. 198578

Westbrook J H 1958 Flow in rock salt structure (Report 58-R L, 2033 of GE Research Laboratory USA)

Wooster W A 1953 Rep. Prog. Phys. 1662 